Encuentro №. 97, 74-83, 2014

\title{
La gracia y el arte de habitar en la luz: comentario al libro Luz habitada de Luis Rocha Urtecho
}

Jorge Alvarado Pisani*

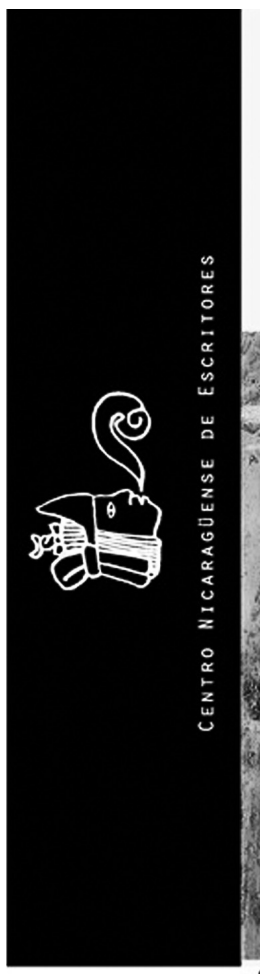

\section{Luz habitada}
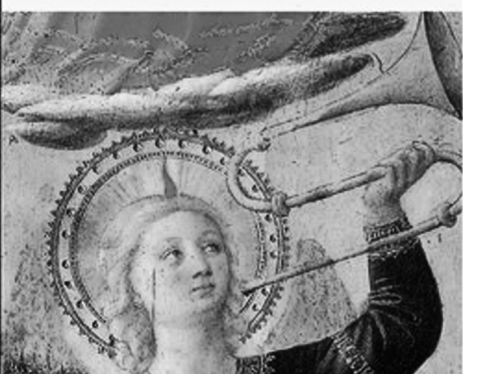

oxph

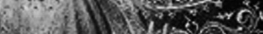

Whe 1 y $(5) e^{5}$
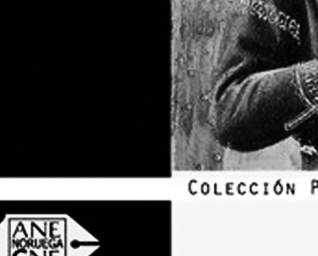

ANE -

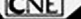

Esta es una historia de comunicación, comunión, comunidad y comunismo trinitario de vida, amor y libertad de tres seres de Luz Celeste -el Padre-Madre, el Hijo-Río y la Espíritu Santa- con tres seres de Luz Terrestre y Palabra Inspirada -es decir, tres luminosos poetas-. Para hacer canto, cuenta y cuento de esta historia habrá que comenzar por el principio, pero no por cualquier principio sino por el principio principal, el propio principio de todos los principios:

Oficina de Planificación y Gestión de la Información, Universidad Centroamericana - UCA, Managua. 
Jn 1:1.9.15

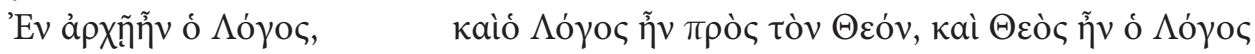
La Palabra, al principio, era. Y hacia Dios la Palabra era.Y la Palabra, Dios era.

(...)

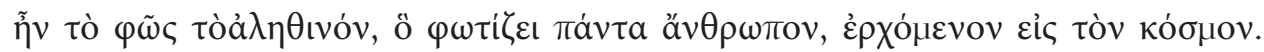
Luz verdadera que alumbra a todo humano o humana cuando Ella viene a este mundo. (...)

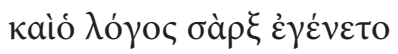

Y se hizo Carne la Palabra.

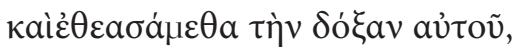

Y vimos su Gloria,

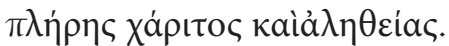

de Gracia y de Verdad plena.

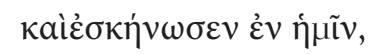

Y habitó entre nosotros.

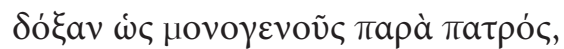
Gloria de Unigénita del Padre,

\section{Y la historia sigue así...}

A los 1899 años terrestres de haber devenido carne infantil la Luz Perpetua, otro niño vio la luz de este planeta el día lunes 2 de un mes de octubre, en una ciudad navarra llamada Lodosa, seguramente por los lodos del Ebro. Y fue bautizado Ángel, por festejarse ese día la fiesta de los Ángeles Custodios. Y este Ángel se hizo jesuita a los 18 años y vivió 54 años más en la Compañía de la Luz, digo, de Jesús. Y habitó entre nosotros en Nicaragua, en 1936, y fue profesor de literatura y lenguas clásicas y modernas, por diez años, en el Colegio Centroamérica de Granada, hasta 1946, y, tras múltiples aventuras y desventuras por Estados Unidos (1946-1947), El Salvador (1948-1954) y México (1954-1961), fue por diez años profesor de filosofía, arte y letras en esta Universidad Centroamericana (UCA) de Nicaragua, entre 1961 y 1971.

Cuando Ángel llegó a la recién nacida UCA, en 1961, tenía 62 años. Por entonces, un joven poeta, periodista y escritor en ciernes de 19 años, Luis Armando Rocha Urtecho -hijo y nieto de poetas, escritores y periodistas, y exalumno del Colegio Centroamérica de Granada, nacido transitoriamente en Ciudad de Panamá, es decir, en rápido tránsito hacia Granada, el día lunes 2 de noviembre de 1942-, ya trabajaba como colaborador-editor del diario La Prensa, y muy pronto fue adoptado por Ángel como su discípulo "benjamín", ahijado y cofrade de los ya ilustres Ernesto Cardenal, Carlos Martínez Rivas, Ernesto Gutiérrez, Ernesto Mejía Sánchez y Fernando Silva. La comunión poética y vital entre Ángel y Luis no dejaría de profundizarse desde entonces, sobre todo al regreso de Don Luis de Rocha y Urtecho, desde Madrid a Managua, en 1965, ya casado con la conquistadora extremeña Doña Mercedes de Gómez y Alcázar, para trabajar junto a Pablo Antonio Cuadra en La Prensa, el Departamento de Cultura y la revista Encuentro de la UCA, y la Revista El Pez y la Serpiente. Justamente en ese año de su regreso a Nicaragua, inspirado por los misterios de su vida con Doña Mercedes, y cada vez más allegado a Ángel, comenzó Don Luis a escribir, "poesía doméstica, uxórica o matrimonial" -para decirlo con palabras de José Coronel Urtecho. Al año siguiente, a estos retornados a Nicaragua y al Edén les llegó su primer poema inmortal, el sábado 13 de agosto de 1966, titulado José Luis Rocha Gómez, nuestro colega y compañero. El "misterio familiar" 
-el concepto es de Gabriel Marcel- que unía a Mercedes, Luis, José Luis y Ángel se le fue haciendo a Don Luis poesía uxórica, uxorial o uxoria entre 1966 y 1968. Por ejemplo, en el poema titulado:

\title{
"Canto que mejor no pudo terminar el poeta"
}

\author{
(...) \\ Y yo que antes quise hacer del poema un coral \\ habitado de poetas y pastores y una estrella. \\ Sólo una. Pero llegó antes la esperanza. \\ Porque la esperanza es buena \\ es muy buena la buena esperanza. \\ Luego todo fue sucediéndose, \\ uniéndose, prevaleciéndonos \\ en su largo llanto intermitente \\ que irrumpe desde el fondo de la noche \\ desde su cuna hasta mi canto. \\ Porque llegar y llorar todo es comenzar. \\ Llanto que prevalece y no desaparece \\ y que se prolonga en ese gesto extendiendo \\ ahora sus minúsculos brazos hacia \\ los dominios lácteos de Dios \\ en la serena paz de hembra de la madre, \\ hembra pacificada, realizada, madre \\ y después boca y senos \\ que se unen \\ que me unen \\ que nos prevalecen \\ y aún alcanzo a oír el etéreo Ángel poeta \\ diciéndome \\ revelándome \\ que este niño es el mejor final de mi poema.
}

Gracias a esta conspiración familiar, las Ediciones de Librería Cardenal situada de donde fue la Iglesia San Antonio media cuadra arriba, costado sur de la Calle Central de Managua- entregaron al público, en los primeros días de octubre de 1968, el cuarto texto de su colección de poesía, titulado Domus Aurea. Los tres primeros títulos de la colección, publicados ese mismo año, habían sido: Mayapán, de Ernesto Cardenal Martínez, Siete Poemas Atlánticos, de Iván Uriarte Baltodano y Agua Arriba, de Fernando Silva Espinoza. Esta primera edición de Domus Aurea, con 22 páginas no numeradas en cuarto mayor $(27 \times 21 \mathrm{~cm}$.), tenía sólo 13 poemas uxóricos, uxoriales o uxorios. Pero ya lo dejó dicho José Coronel Urtecho en sus "Anotaciones sobre Luis Rocha": "Creo que, entre nosotros, nadie dice más, en menos, que el poeta Luis Rocha" (Rocha, 1996, p. 15).

$\mathrm{Al}$ año siguiente, en diciembre de 1969, dos meses después de haber nacido Raquel, segundo poema inmortal de Doña Mercedes y Don Luis, la Editorial y Distribuidora Cultural Centroamericana, dirigida por Ricardo Pasos Marciaq, publicó, como segundo título de su colección "Serie Menor de Lujo" -el primer 
título había sido Agosto, de Pablo Antonio Cuadra-, la segunda edición de Domus Aurea, con 112 páginas en octavo menor (16x8.8cm.), viñetas interiores de Leoncio Sáenz y portada diagramada por el mismo Pablo Antonio Cuadra. El libro tenía ahora 14 poemas, y así ha quedado, al incluir "Mi Virgen de Mercedes":

Una mañana

y desde entonces todas

vi al despertar

un rostro lleno de amor

y era la virgen

como siempre barriendo

arreglando el día

mientras más allá

nuestro niño jugaba.

El inmensamente generoso José Coronel Urtecho dedicó 13 de sus 46 "Anotaciones sobre Luis Rocha" a esta segunda edición de Domus Aurea. Una de estas anotaciones dice así:

La primera [sic; debería decir 'la segunda'] edición de Domus Aurea, un precioso librito, hecho no sólo con gusto sino con amor, sugestivamente ilustrado por Leoncio Sáenz, es para mí una joya bibliográfica, impresa en Managua en un tiempo nefasto, en el que casi nada se editaba y menos libros de poesía en ediciones de esa calidad.

Esta segunda edición de Domus Aurea salió de imprenta el miércoles 3 de diciembre de 1969 y cinco días después, el lunes 8 de diciembre, día de la Inmaculada Concepción, el poeta Luis le regaló a su "Pater" Ángel un ejemplar de Domus Aurea con la siguiente dedicatoria:

Para Ángel, nuestro padrino y padre y Ángel -padriángel-, esta segunda edición de su DOMUS AUREA, con el amor que en Ti me tienes y que en Ti te tengo.

Luis Rocha. 8(fecha de mi bautizo)/12/69.

Y, a su vez, el Padre Ángel, para corresponder al regalo, tuvo la original y poética idea de comprar otro ejemplar de Domus Aurea y regalárselo a su ahijado Don Luis incluyéndole, como dedicatoria, el poema autógrafo titulado "Luz habitada":

\section{Luz habitada}

Sin llegar a la luz,

por su hermosura

la paz que da el reposo

en la luz misma

que no se ve y nos ilumina todo.

Gracia de ser y ser en todo hermosa,

de hacer hermoso todo lo que mira:

Claridad que es, ya en mí, luz habitada,

no ver la luz y ver que es luminoso

todo, porque la luz nos ha mirado, porque la hemos mirado y no sabíamos

que era la luz en una forma humana: 
Claridad de una casa en que el cielo entra y en que entrar en la casa es ver el cielo de quien habita en luz su luz mirada. Sin llegar a la luz, por la luz misma, ver que son resplandor de un día pleno de dos, las dos auroras que nos miran con todo el pleno día en sus miradas. Descanso de la luz en casa y cielo: Entrar y verlo todo en ese gozo claro de verme en mí con cielo y casa. Y este reposo en paz de una hermosura con que todo es en mí luz habitada.

$$
\text { Ángel S.J." }
$$

Pero la cosa no quedó, así no más, en ese ejemplar de Domus Aurea, con el poema de Ángel anidado entre sus hojas, sino que el poema se le metió a Luis por los ojos y le llegó al corazón y le habitó por 45 años el útero poético hasta que el poeta comenzó a sentir dolores de parto y dio a luz este otro libro que estamos presentando y que tiene el mismo poema de Ángel anidado entre sus hojas y que se llama, claro está, Luz habitada.

Luz habitada es un libro de 70 páginas en octavo mayor $(21 \times 14 \mathrm{~cm})$, publicado en la Colección Poesía del Centro Nicaragüense de Escritores (CNE). Contiene 33 poemas: el de Ángel ("Luz habitada”), una carta-poema de José María Valverde (“Carta a Luis Rocha, en Nicaragua”) y 31 poemas de Luis, agrupados en dos partes: ÁNGELUS, con 6 poemas de tema angélico, y ÁNIMUS, con 25 poemas sobre la libertad, la natividad de Jesús entre los pobres, y el amor uxorio y la conciencia ustoria del ardiente Don Luis. Ambas partes están precedidas por sendas ilustraciones del Padre Maximino Cerezo Barredo CMF, llamado "el pintor de la liberación": una Anunciación a María, para ÁNGELUS, y una alegoría de la Espíritu Santa, o quizás del Ave de Noé después del Diluvio, para ÁNIMUS. Y, para que todo quede entre ángeles, la portada de Luz habitada está iluminada por uno de los doce ángeles instrumentistas que circundan el retablo de la Madonna dei Linaioli, pintado por el dominico Fray Juan de Fiésole, il Fra Angélico (1390-1455), para presidir el recinto de la Logia de los Tejedores de Lino en la Ciudad de Florencia. Con todo esto, Luz habitada no cede un punto de belleza a Domus Aurea como joya bibliográfica. La presencia del Ángel Clarinero o Ángela Clarinera en el portal del libro no es un capricho iconográfico sino que está sonando su clarín porque -para que se haga la Luz así en la tierra como en el cielo-, este libro es una nueva Domus Aurea de Luz habitada.

\section{Los habitantes de Luz habitada}

Abora bien, ¿quiénes son los habitantes de esta Luz habitada que se nos anuncia con tan claro clarín en el libro de Don Luis? Nada más entrar en ella, vemos que nos abre la puerta de la casa, abrazada por Don Luis, la conquistadora extremeña, Doña Mercedes de Gómez y Alcázar de Rocha y Urtecho, que por amor cruzó la mar atlántica desde su Extremadura natal (Solana de los Barros, Provincia de 
Badajoz) para fundar la Extremadura de los Rincones en el Monte de los Venados, es decir, en Masatepe, de Nicaragua. También vemos que habitan, en la nueva Domus Aurea, José Luis, Raquel, María Mercedes y Ximena, los cuatro poemas inmortales de Don Luis y Doña Mercedes. Y nos encontramos por todos los rincones con la recia ternura, la risueña picardía, la erótica uxórica y la furia libertadora de Don Luis. Pero nos encontramos también, no faltaría más, con la Madonna María, el discreto San José y el amado Jesús de Nazaret. Y con el Padre Ángel y su sobrino más feo, Jesús Mari Martínez Paternain. Y con el Padre Emilio del Río S.J., ángel custodio de Ángel. Y con un jubiloso coro de ángeles llamados Pablo Antonio Cuadra, José Coronel Urtecho, Pedro Joaquín Chamorro Cardenal, Fernando Silva, Joaquín Pasos -el Ángel Pobre-, Luis Favilli, Augusto C. Sandino, Vidaluz Meneses, José María Valverde, Tito Castillo, Rosa Carlota y Carlos Tünnermann, Mario Urtecho, Manuel Obregón, Onofre Guevara, Emilio Pérez, Clarita Blanco, María Elsa Vogl, Kirsti Blom, Klaudhia Artola, Luis Javier Espinoza Rocha y hasta el Zorro, Sandokán, Barbarroja y Aladino. Así como también podemos sentir una alegre algarabía de ángeles y ángelas menores, devotos del Padre Ángel, que andan dando vueltas por allí, metiendo las alas por todas partes sin dejarse ver, como las y los que acompañaron al Poeta Rocha, a Doña Mercedes y a Don Jesús Mari Martínez a bautizar en Extremadura de Los Rincones, el miércoles 24 de agosto de 2011, una espléndida ceiba que desde entonces se llama "La Ceiba del Ángel”. Junto a tal ejército de Ángeles Custodios o Ángeles de la Guarda, de clara y fiel luz, también se insinúan en el libro algunos que otros ángeles de luz amarga y proterva. Pero el poeta no los deja estar en la Luz habitada y los envía de regreso a los campos de piedra quemada de su otro libro Me quema la palabra.

\section{El misterio de la luz habitada}

Recordemos que Ángel escribió, en la dedicatoria de Domus Aurea al autor de Domus Aurea: "Este ejemplar de la Casa de Oro es para su autor con otra casa -suya- como Luz habitada". Y a renglón seguido, los 22 versos del poema "Luz habitada". ¿Qué dice Ángel aquí, cuál es la otra casa que entrega a quien ya tiene "Casa de Oro”? ¿Es este mismo poema, "Luz habitada", la otra casa que Ángel entrega a Don Luis, como si él fuera apenas un amanuense, un ángel-mensajero, del poema que en ese instante se instala como en su casa dentro de la "Casa de Oro"? ¿O la casa que Ángel entrega es la misma casa alquilada en que viven Don Luis y Doña Mercedes, con José Luis de tres años, y Raquel, de tres meses, pero habitada por otra luz? ¿Quién habita la "luz habitada" que ha visto Ángel en el libro Domus Aurea y en la casa de Don Luis y Doña Mercedes?

Ángel no dice que él mismo habite en la luz ("Sin llegar a la luz...") sino que, "por su hermosura", por la hermosura de la luz, él ha alcanzado "la paz que da el reposo en la luz misma que no se ve y nos ilumina todo". Y que esa luz tiene la "gracia de ser y ser en todo hermosa, de hacer hermoso todo lo que mira". Y que esa luz -la "luz habitada" que ya está en él-es una forma de "claridad que es... no ver la luz y ver que es luminoso todo, porque la luz nos ha mirado, porque la hemos mirado y no sabíamos que era la luz en una forma humana”. Una forma de claridad que es la "claridad de una casa en que el cielo entra y en que entrar en la casa es ver el 
cielo de quien habita en luz su luz mirada". Entonces entendemos claramente que la luz, que no se ve, está habitada por la luz del cielo en esa casa. Por eso, "sin llegar a la luz, por la luz misma", el Ángel vidente alcanza a "ver que son resplandor de un día pleno de dos, las dos auroras que nos miran con todo el pleno día en sus miradas". Pero aquí el poema nos deja estupefactos. Ya no es una sola luz la que mira, sino que son dos auroras las que nos miran con todo el resplandor del día pleno de ellas dos. ¿Son esas dos auroras los dos ojos aurorales de una sola luz que resplandece en los ojos del Ángel que ha llegado a ver dos auroras que le miran a él, y a todo miran? ¿O son dos luces distintas, cada una con luz propia, las que él mira? Hagamos cuentas. Si la luz habitada es la luz invisible que hace todo hermoso, y es también la luz en forma humana que nos mira con el resplandor de dos auroras, tenemos entonces tres luces en una sola luz que no es luz sola sino luz trina. De modo que la Luz habitada está habitada nada más y nada menos que por la mismísima Santísima Trinidad, entrevista por Ángel tanto en la casa de palabras que es la "Casa de Oro" (Domus Aurea, el libro) como en la "Casa de Oro", Domus Aurea, que es la Madonna, Nuestra Señora de la Luz, así como también en la casa alquilada donde viven el poeta Luis con su esposa y un niño chavalito y una niña tierna que dan casa y cielo al Ángel mensajero de la luz habitada. Y así resulta que la luz habitada es la misma Luz del Amor entrevista por Ángel una noche, en un instante de iluminación poética y de iluminación trinitaria, como dice Ángel mismo en el soneto titulado "Por la iluminación de aquel instante":

Por la iluminación de aquella hora,

Luz de esta noche. O día entre vislumbres

que da en lejano resplandor de cumbres

El que en su Luz inaccesible mora.

El que es siempre en su pleno día aurora

de Sí en un Hijo, y su Hijo en muchedumbres

de hijos que a Él van con lumbre de las lumbres

de esta noche de sangre que el sol dora.

Suena en su eternidad la hora anunciada

y el amor sube en sucesión constante

que es gozo, en cada paso, de llegada

al gozo pleno de un sentir radiante

la inaccesible Luz, luz habitada

por la iluminación de aquel instante.

Que la interpretación trinitaria del poema-dedicatoria "Luz habitada" no es inverosímil puede mostrarse si comparamos su contenido con lo expresado por Ángel al P. Juan Bautista Bertrán S.J., en una carta de 1964 (del Río, 2011, pp. 37 38):

(...) A propósito del saber ver, el saper vedere de Leonardo, en que ponía él la esencia de la pintura y del ser pintor, veo yo cumplirse (...) no ya exclusivamente la pintura, sino todo el arte y toda la ciencia. Y elevándose cuanto se puede elevar ese saper vedere, que en ello consiste y con ello se conjuga toda la espiritualidad y toda la santidad. No sólo es el más alto don del artista, sino del hombre. Por eso, entrar en el descanso no es sino llegar a ver con plenitud, totalmente. Así, la última poesía, la poesía definitiva, no será sino la de una revelación total. Y poseerla no será sino haber aprendido totalmente a ver: que ya el aprender 
se haya hecho "aprehender", cuando la potencia visual nuestra, nuestra luz, haya sido de tal modo elevada, se haya hecho de tal modo divina: participante (revelado consorte) del que habita una Luz (la Suya) inaccesible, que en su luz y con su luz veamos la Luz. (Entonces con tu luz la Luz veremos). Nunca ahondaremos suficientemente en ese saber que pasa, por todos los grados por los que el hombre se puede elevar, hasta esa mirada en los ojos, de la mente, de todo el ser hecho ojos, como los serafines: ojos en los mismos ojos, los ojos infinitos de Dios en los nuestros, y a la que ha de corresponder el inflamarse del corazón, de la voluntad con todo el ser, elevado él ya también, de modo que pueda con su amor amar al Amor, como con su luz ha visto la Luz. Por todos los grados, digo. Aun en los que aquí se pueden dar. Hasta podemos decir que, entendiéndolo como se debe, todo ser, todo cuerpo, podríamos decir, al que miramos mucho, sabiéndolo ver, acaba por dejarnos, como el de Cristo a los apóstoles en la Ascensión, mirando al cielo en que se nos pierde.

Por último, para rizar el rizo del misterio, cabría preguntar si el bellísimo tropo "luz habitada”, creado por Ángel y recreado por Luis Rocha, tiene algún precedente en la literatura española. Tal pregunta pudiera parecer impertinente, irrespetuosa y desvariada pero espero que la posible respuesta nos lleve a admirar aún más, si cabe, a Ángel y a Luis como pájaros poéticos de muy alto vuelo. Porque la posible respuesta es que el tropo "luz habitada" vio la luz por obra y gracia del genio poético de Luis Rosales, quien lo usó en una décima, publicada en 1939, que luego reelaboró en dos cuartetas que así quedaron en su libro Rimas, de 1951. En efecto, en la revista Isla, segunda época, número 18-19 (Rosales, 1939), editada por Pedro Pérez-Clotet en Jerez de la Frontera, Provincia de Cádiz, en 1939, se leen tres décimas de Luis Rosales tituladas "Luz en la orilla", "Aquella lluvia dorada" y "Tarde de asombro en Castilla", que se convertirán en las rimas tituladas, respectivamente, "Luz, al largo de la playa”, "Durar, también es vivir" y "La lluvia, que hizo aquel bien” (Rosales, 1951, pp. 41 y 47). El ejemplar de Rimas consultado para esta investigación era propiedad del P. Ángel, está depositado en el Instituto de Historia de Nicaragua y Centro América (IHNCA) de la UCA (cota IHNCA-PAM-0492) y tiene muchas anotaciones manuscritas de Ángel, a lápiz, y también, escrito en tinta (p.68), el bellísimo poema de Ángel, titulado "El silencio de Luis", al pie de la rima "Ayer vendrá" de Rosales.

$\begin{aligned} & \text { LUZ EN LA ORILLA } \\ & \text { (Sardinero) }\end{aligned}$
El mar, que ayer con la bruma
era un resplandor vencido,
hoy con el sol ha tenido
toques de presencia suma;
y ha vuelto a nacer la espuma
con el movimiento, y brilla
sobre la tierra sencilla
la dulce luz habitada,
la transparencia dorada
que muere junto a la orilla.

LUZ, AL LARGO DE LA PLAYA

La luz que del cielo vino, la luz que del cielo viene, ya, junto al mar, se detiene, ¡quizás no sabe el camino!

Ya, dentro del mar, no brilla carnal, sino reflejada, la dulce luz habitada que muere, junto a la orilla. 
He aquí la décima de 1939 y la rima de 1951:

La posible respuesta se hace más verosímil si recordamos que la persona y la palabra poética de Luis Rosales calaron muy hondo en la palabra y la persona de Ángel Martínez. Como prueba de tal comunión y comunicación poética valgan los siguientes párrafos de una carta de Ángel, escrita desde San Salvador, el 23 de febrero de 1950, al futuro filósofo P. Franco Díaz de Cerio S.J., por entonces maestrillo del Colegio Centroamérica de Granada (del Río, 2011, p.430):

(... ) Pasaron por aquí poetas. De los cuatro que venían por estos rumbos, sólo llegaron Rosales y Zubiaurre a El Salvador -a Nicaragua fueron los cuatro, los dos dichos y Foxá y Panero-. Yo esperé su llegada a Nicaragua cuando yo estaba allí, y me hubiera alegrado mucho, por estar allí mucho más en ambiente. Eso sin contar con que Rosales, según me dijo, venía con muchas ansias de ver mi Río (...El Río que yo he dado a luz de nuevo, en los versos...) Se anunciaron allí y yo hablé por radio y escribí unos artículos. Pero se retrasaron. Aquí llegaron de improviso y pasaron rapidísimo -dos días-. Fue lo suficiente, no para que los conocieran pero sí para que yo viviera a Rosales, con quien venía viviendo hace como diez o doce años. (...) Con Rosales tuve ya desde el principio una fusión completa. Lo esperé en la Legación de España. Y cuando apareció -lo conocía bien por sus retratos- me fui a él, y por toda presentación le dije un verso suyo: “-Sí. Ya conozco esa luz que no recuerdo”. Después vino un abrazo y él continuó: “-Que no puedo recordar, porque la estoy viviendo todavía”. Venía cansado de la lucha y de los recitales, que no son para su poesía. Tenía ganas de leer en la intimidad, sólo a tres, o a lo más cuatro, su Casa encendida. Y yo le preparé una casa encendida donde encendiera él la suya y donde se encendiera él hasta el rojo blanco. Es la mayor experiencia que he tenido de un hombre totalmente encendido, experiencia de una pura llama. Si tiene V. ocasión, no deje de tener ese libro capital suyo que es La casa encendida. Yo la había leído dos veces, pero él me la hizo ver como si nunca la hubiera visto encendida hasta la inflamación serena con que veríamos la vida, si la vida pudiera verse por algo más que por sus efectos de vida en los vivientes.

Así, pues, parece por lo menos muy probable que el tropo "luz habitada", creado por Luis Rosales en los años previos a la guerra civil española, hubiese anidado en la conciencia poética de Ángel incluso antes de conocer en 1950 en persona a Luis Rosales, “con quien venía viviendo hace diez o doce años”. Si esto es cierto, no se trataría ni de imitación ni de préstamo inconsciente sino de una verdadera y fecunda recreación poética, teológica y mística de la figura "dulce luz habitada" traspuesta, por obra y gracia de Ángel, a clave trinitaria, y luego, por obra y gracia de Luis Rocha, a clave uxoria y ustoria.

Si Rosales, en 1939, siente y dice que la "tierra sencilla" de la playa santanderina del Sardinero está dulcemente habitada por la "transparencia dorada", por la "presencia suma”, de la luz solar, Ángel, en 1967, en un instante de nocturna iluminación, siente y dice que su amor "sube en sucesión constante que es gozo, en cada paso, de llegada al gozo pleno de un sentir radiante la inaccesible Luz, luz habitada por la iluminación de aquel instante". Y poco tiempo después, en 1969, siente y dice que la Domus Aurea, la Casa Dorada, de Luis Rocha, resplandece de luz habitada por el Amor que los une en la tierra y en el cielo de aquella casa donde un 
poeta y su esposa, un chavalito y una tierna dan casa y cielo al Ángel mensajero de la luz habitada. Y, 45 años después, en nuestro aquí y ahora de Managua y 2014, el poeta Rocha siente y dice, en su Luz habitada, que la presencia y la palabra poética de Ángel son "como la cumbre de esta ceiba (La Ceiba del Ángel) cuyas majestuosas ramas nos aferran a tanta claridad de espacio que en ti es ya luz habitada” (p.25), y al final de esa Luz habitada les pide a sus hijos, en nombre suyo y de Doña Mercedes, cumplir su última voluntad cuando les llegue el día del último viaje:

Únannos y reúnannos, mézclennos, revuélvannos y láncennos

al viento y al cielo en señal de respeto filial

a lo aquí decidido, y en reconocimiento a nuestra libertad.

Así albérguennos en los recovecos de su nostalgia

y piensen que si fuego fuimos, al fuego nos debíamos

y que nos vamos felices de volar en volátiles cenizas.

Habitantes del reposo en paz, en la hermosura

de ser al fin luz por nosotros habitada.

Y esta es la historia doblemente trinitaria que comenzó al Principio de todos los principios con tres Personas distintas de una sola Luz Verdadera y que hemos visto y oído culminar en la comunión y comunicación y comunismo de tres Poetas distintos poseídos por el mismo Amor verdadero a (y de) la Palabra de luz habitada. Esta es la historia de una verdadera comunión, comunicación y comunismo poético que el torpe ángel trompetero que les habla ha intentado contarles a ustedes esta noche en nombre de los dos Luises y el Padre Ángel y también en el Nombre del Padre-Madre, el Hijo-Río y la Espíritu Santa. Amén.

Y como colofón...

Ovillejo de la foto en la solapa

Como Francisco de Asís - Don Luis -

ni teme ni se encolocha - de Rocha -

y huye del ruido y del cuecho - y Urtecho -

Un fulgor le abrasa el pecho

y él abraza, en la verdura,

al Sol de su Extremadura,

Don Luis de Rocha y Urtecho.

Estas palabras fueron leídas por el autor durante la presentación del libro "Luz habitada” en el Auditorio Xabier Gorostiaga, S.J. de la Universidad Centroamerica (UCA), el 31 de enero de 2014.

\section{Referencias bibliográficas}

del Río, E. (ed.). (2011). Con el Hijo del Hombre. Las Cartas. Managua: Universidad Centroamericana.

Rocha, L. (1996). La Vida Consciente. Managua: Centro Nicaragüense de Escritores y Editorial Nueva Nicaragua.

Rosales, L. (1939). El grito de la tierra silencioso. Isla, (18-19), 2-3.

Rosales, L. (1951, 25 de agosto). Rimas 1937-1951, (2da ed.). Madrid: Ediciones Cultura Hispánica. 